\title{
Humane Harvesting Initiative: The Influence of Harvest and Post-Harvest Handling Practices on Fish Welfare and Product Quality
}

\section{Barbara Rasco $^{1 *}$, Kenny Down ${ }^{2}$ and Mahmoudreza Ovissipour ${ }^{1}$}

${ }^{1}$ School of Food Science, Washington State University, Pullman, WA 99164-6376, USA

${ }^{2}$ Blue North Inc., Seattle, WA, 98109, USA

\section{Introduction}

Fish offers the most promising source for meeting the increased demand for safe, highly nutritious protein food. Wild fisheries provide $60 \%$ of the seafood currently used for human and animal consumption. Fisheries are subjected to social constructs, just like terrestrial animals, and social constructivism impacts regulations, product availability and quality, consumer acceptance, and how fishery products are marketed, particularly in the developed world. One of the important emerging concerns is with animal welfare including the pre-slaughtering and slaughtering practices used. Technically, welfare is difficult to define and measure, however, there are several indicators that are indicative of animal welfare and which are applicable to fish. Generally, animal welfare is incorporated into good production practices, and at the end of the animal's life involves management practices that avoid stress. Reduction of stress has been shown to increase the physical quality and nutritional value and subsequently shelf-life of fishery products.

One of the first studies on humane animal slaughtering was conducted in 1853 by Benjamin Ward Richardson. From his work, different animal welfare societies were established and organized in the United States and elsewhere. One of the first federal laws passed on humane slaughter was P. L. 85-765 signed into law by President Dwight D. Eisenhower on August 27, 1958. This Act requires all meat packers selling to the U.S. government to provide anesthetization or instant stunning by mechanical or electrical means prior to the slaughter of cattle, calves, horses, mules, sheep, swine and other livestock, except in the case of kosher slaughter. The law covers 80 percent of the livestock slaughtered.

Consumers have recently become more concerned with the welfare of fish with respect to humane production, harvesting, and post harvesting procedures, but unlike livestock there are few laws or regulations addressing humane practices. Recently, many researchers have studied the influence of the stress conditions on fish physiology in aquaculture systems as well as the effect of stress of flesh quality. While the aquaculture industry has begun looking and moving in the direction, the wild commercial harvesters have not. Aquaculture is a growing industry and maintaining husbandry conditions to alleviate stress to the greatest extent possible is not only the ethical thing to do, but is a good business practices. Culturists can manage a number of conditions related to stress including stocking density, water quality, oxygen level, exposure to and treatment of disease, quality of feed, handling and transport and breeding practices.

Here we are focusing on harvesting and post harvesting procedures and means to decrease stress conditions in the wild Alaska Cod hook and line fishery. Similar to other animals, fish can feel pain and respond to stress in many of the same ways other vertebrate animals do. Physiological responses of fish to stress include an increased production of adrenaline, noradrenaline and cortisol with physical manifestations of increased heart rate and vigorous muscle contractions, all of which are reversible when the stress response is removed, with physiological parameters returning to normal within hours. It is not possible to remove all stress from cultivation or harvesting environments, however, inhumane conditions are presumed if the challenge is not removed as quickly as possible and stress is prolonged unnecessarily.

Quality changes start with changes in blood glucose and cortisol levels, two important biochemical indices for stress. A rapid decrease in energy reserves, mainly adenosine triphosphate (ATP), with a concomitant increase in lactic acid and drop in post mortem muscle $\mathrm{pH}$ is also observed. Fish under the greatest amount of stress during harvesting, go into rigor mortis very rapidly and the quality of the fillets is adversely affected and exhibit high drip loss and softening of the muscle texture. In addition, harvesting and post harvesting stress increases oxidation of polyunsaturated fatty acids (PUFAs) from the production of reactive oxygen metabolites (ROMs). Fish PUFAs have several benefits for humans such as promotion of healthy blood lipid profiles, reduction in the severity of rheumatoid arthritis, and improvements in cognitive development in infants and neurological health in aging adults. In addition, stress conditions during harvesting and post-harvest processes can induce peroxidase and aldehyde production in the fish fillet during the short term storage, which can decrease the nutritional quality of the fish fillet. As a result, consumer acceptance will be decreased due to the adverse changes in texture and flavor from the stress associated degradation of fatty acids and protein.

Since seafood products are consumed in part due to their high nutritional value and quality, producers should be concerned about how improvements to animal welfare would be of benefit to them. Utilizing catch methods that could decrease fish stress should be considered. Many researchers have studied different harvesting method and their impact on fish quality. For example, Blue North Inc. in Seattle, WA, not only improved the hook-and-line gear for wild Alaska line-caught cod, but also they are constructing an innovative hook-and-line fishing vessel which will be the new flag ship of the company, deemed "the new F/V Blue North" . Their "Moon Pool" technology on this new generation of fishing vessel involves conveying hooked fish directly from the water through an entrance port in the bottom of the vessel to a stunning table before the conventional slaughter table. This method decreases the stress on fish during the harvesting procedure by putting the central nervous system to sleep prior to bleeding or immersion in bleeding tanks. This is accomplished by allowing the crew access as the fish breaks the surface of the water. In the new generation vessel this is further enhanced in a climate controlled interior compartment. Fish

*Corresponding author: Barbara Rasco, School of Food Science, Washington State University, Pullman, WA 99164-6376, USA, Tel: 509-335-1858; E-mail: rasco@wsu.edu

Received December 15, 2014; Accepted December 18, 2014; Published January 21, 2015

Citation: Rasco B, Down K, Ovissipour M (2015) Humane Harvesting Initiative: The Influence of Harvest and Post-Harvest Handling Practices on Fish Welfare and Product Quality. J Aquac Res Development 6: 303. doi:10.4172/21559546.1000303

Copyright: (C) 2015 Rasco B, et al. This is an open-access article distributed under the terms of the Creative Commons Attribution License, which permits unrestricted use, distribution, and reproduction in any medium, provided the original author and source are credited. 
Citation: Rasco B, Down K, Ovissipour M (2015) Humane Harvesting Initiative: The Influence of Harvest and Post-Harvest Handling Practices on Fish Welfare and Product Quality. J Aquac Res Development 6: 303. doi:10.4172/21559546.1000303

Page 2 of 2

are handled and stunned in this area within seconds, thus reducing the risk of injury and bruising. Key to post-harvesting handling is time. Blue North has developed the most humane method available for its fishery by keeping the time between harvesting and slaughtering as short as possible and involving a stunning step immediately as the fish are landed. Several methods have been studied and applied by industry including asphyxiation, asphyxiation in ice, bleeding when fish are conscious, percussive stunning, spiking and electrical stunning. The best methods are ones that are most effective for a particular specie and which have the least impact on product quality. Recently, Blue North Inc. installed a new technology on longliners which is percussive followed by immediate bleeding, decreasing the time between harvesting and processing. This humane practice increases the quality of the fish, can prevent gaping and reduce lactic acid production in the muscle. Bleeding is a widely recognized method for improving fish quality by improving color, physical appearance, and decreasing lipid oxidation. Humane practices clearly provide benefit and should be widely adopted both by fishers and aquaculturists as best practices. 